\title{
Cyclodextrin conjugated ferritin nanocages reduce intracellular cholesterol level in foam cells
}

\author{
Samyukta Ravishankar ${ }^{1}$ and Sierin $\operatorname{Lim}^{1,2}(\bowtie)$ \\ ${ }^{1}$ School of Chemical and Biomedical Engineering, Nanyang Technological University, 70 Nanyang Drive, Blk N1.3, Singapore 637457, Singapore \\ ${ }^{2}$ NTU-Northwestern Institute for Nanomedicine, Nanyang Technological University, 50 Nanyang Drive, Blk N3.1, Singapore 637553, Singapore
}

(C) The Author(s) 2019

Received: 16 July 2019 / Revised: 21 September 2019 / Accepted: 23 September 2019

\begin{abstract}
Accumulation of lipid-laden macrophages (foam cells) is characteristic of atherosclerosis development in the arterial walls. Ferritin nanocages have been found to passively accumulate in the atherosclerotic plaque. Ferritin has been actively investigated as a carrier for contrast agents in atherosclerosis diagnosis. We demonstrate the potential of ferritin as a carrier for therapeutic molecules to mediate cholesterol reduction from foam cells. Cyclodextrin molecules are chemically conjugated to the ferritin nanocages surface or encapsulated within the nanocages using metal co-loading methods. The cyclodextrin-conjugated ferritin has nanomolar affinity to cholesterol molecules. Treatment of foam cells with the conjugates shows decreased levels of intracellular accumulated cholesterol. The preferential localization of ferritin to foam cells is due to transferrin receptor-mediated endocytosis process. These findings show that ferritin nanocages as carriers localize cyclodextrin molecules to foam cells which mediate intracellular cholesterol reduction, thus highlighting its potential use as a therapeutic agent.
\end{abstract}

\section{KEYWORDS}

cyclodextrin, ferritin, protein nanocages, cholesterol sequestration, foam cells

\section{Introduction}

Atherosclerosis is the leading cause of mortality globally [1]. Changes in diet, exercise and cholesterol lowering drugs such as statins, are prescribed in response to atherosclerosis diagnosis. Statins, being a preventive drug, maintain cholesterol homeostasis but contribute minimally to plaque area reduction and cause side effects such as muscle degeneration with chronic use [2]. Other experimental therapeutic approaches include gene therapy to knock down low-density lipoprotein receptors (LDLR) to minimize intracellular cholesterol accumulation and use of recombinant retroviruses to express antioxidants thereby reducing reactive oxygen species (ROS) mediated atherogenesis. However, stability of the vectors, scalability issues, and cost of these methods have limited their clinical translation [3]. To overcome these limitations, other approaches for foam cell targeting and atherosclerosis regression that could be used in conjunction or as an alternative to current therapeutic approaches are being investigated.

Atherosclerosis is characterized by the accumulation of oxidized low-density lipoproteins in the arterial wall and the recruitment of monocytes in developing plaques. The synergistic effect of increased expression of adhesion molecules and the influx of cholesterol containing lipoproteins results in the transmigration of the monocytes into the intima, its differentiation into macrophages, and the formation of foam cells $[4,5]$. These lipid-laden macrophages (foam cells) have been recently identified as biomarkers for the progression of atherosclerosis and are being explored as potential targets for atherosclerosis treatment [6].

Nanoparticles for biomedical applications such as treatment and biomedical imaging have been an active research area. Particles with sizes between 10 and $300 \mathrm{~nm}$ are found to be optimal to ensure sufficient circulation time and minimal toxicity [7]. Examples of nanoparticles that have been introduced to address atherosclerosis include reconstituted high-density lipoproteins, poly(lactic-co-glycolic acid) (PLGA) nanoparticles, lipid carriers and protein-based nanoparticles [8-11]. Distinct from other nanoparticles that require capping agents, proteins naturally exist as monodispersed particles without aggregating under physiological conditions [12]. This facilitates the ease of predicting optimal dosage requirements of the therapeutic molecules co-delivered with the proteins. Ferritin, a protein composed of 24 polypeptides forming a cage structure, is an iron storage protein that stores insoluble ferric compounds intracellularly thus maintaining cellular iron homeostasis. Human ferritin has been found to localize in the plaque region and be taken-up by macrophage cells by receptor-mediated endocytosis upon intravenous administration. The ferritin is found to localize in the lesion sites for up to a duration of $48 \mathrm{~h}$ before being degraded by proteases [13]. Vessel walls in atherosclerotic tissues have gaps in the endothelial lining allowing extravasation of nanoparticles to the site of interest. Nanoparticles are proposed to enter the interstitial space via the adventitia through dysfunctional micro-vessel network formed during angiogenesis. They subsequently localize in the interstitial space following enhanced permeability and retention (EPR) effects $[14,15]$. Ferritin has been previously proposed to be used as potential candidate for diagnostic imaging with properties desired for magnetic resonance imaging (MRI) contrast agents [15-18].

Taking advantage of ferritin's natural preferential accumulation in the plaque, it's therapeutic potential can be thus harnessed by conjugating molecules that mediate cholesterol efflux from foam cells. Our work makes use of Archaeoglobus fulgidus derived ferritin with two amino acid modifications (K150A/R151A; AfFtnAA) that are formed by the self-assembly of the 24 polypeptides into a nanocage 
of $12 \mathrm{~nm}$ [19]. AfFtnAA is a closed pore mutant with controllable self-assembly property in response to ionic strength or metal loading. Co-loading of small molecules such as drugs with metal ions results in encapsulation of high concentration of the drugs in its hollow core of $\sim 8 \mathrm{~nm}$ in diameter. Ease of surface modification allows for the conjugation of small molecules or antibodies using chemical conjugation or genetic fusion strategies [20]. In this study, cyclodextrins (CDs) are chosen as the candidate to mediate cholesterol reduction in vitro. CDs have been known to have high affinity to cellular cholesterol and thereby can promote solubilization or removal of cholesterol from foam cells $[21,22]$. CD and its derivatives are United States Food and Drug Administration (US FDA) approved natural glucose oligomers (found as by-products of starch degradation) used as complexing agents to solubilize and deliver hydrophobic drugs $[23,24]$. Subcutaneous administration of 2-hydroxypropyl$\beta$-cyclodextrin in hypercholesteraemic mice models induced atherosclerotic regression by about $45 \%$ [25].

This work is a proof-of-concept study demonstrating the use of cyclodextrin-ferritin nanocage conjugates (AfFtnAA-CD) as a cholesterol sequestering agent from foam cells. Here, molecular interaction studies using biolayer interferometry shows nanomolar range binding affinities between free cholesterol molecules and AfFtnAA-CD. The intracellular cholesterol reduction capacity of the construct is quantified using enzymatic assay. Uptake studies using inductively coupled plasma mass-spectrometry (ICP-MS) and fluorescence imaging confirm the passive localization of ferritin to cholesterol loaded foam cells in comparison with methyl- $\beta$-cyclodextrin $(\mathrm{M} \beta \mathrm{CD})$ molecules. Using in vitro foam cell models, we highlight the potential use of engineered protein nanocages as theranostic carriers for cyclodextrin to mediate atherosclerosis regression.

\section{Results}

\subsection{Conjugation and loading of cyclodextrin in ferritin protein nanocages}

Small molecules can be incorporated onto protein nanocages on the external and internal surfaces. Figure 1 shows the two approaches used in this work where CDs are chemically conjugated to the external surface of AfFtnAA nanocages or loaded in the inner cavity. Conjugation of $\beta-C D$ to the AfFtnAA has been achieved by copper(I)-catalyzed azide/alkyne cycloaddition (CuAAC) reaction. The conjugation requires modification of AfFtnAA external surface to incorporate cysteine amino acids for reaction with maleimide based linker. The cysteine-modified AfFtnAA (AfFtnAA/E94C) has been produced and purified. Basic characteristics of the unloaded protein subunits (Apo-AfFtnAA) is verified using sodium dodecyl sulphate-polyacrylamide gel electrophoresis (SDS-PAGE) presenting a thick band at $20 \mathrm{kDa}$. The AfFtnAA cage structure is observed to remain intact after the cysteine modification with the resulting hydrodynamic diameter of $\sim 14 \mathrm{~nm}$ after iron-mediated cage formation. The self-assembly characteristic upon iron loading is consistent to previously reported data on AfFtnAA [19] (Fig. S1 in the Electronic Supplementary Material (ESM)).

The relatively insoluble $\beta$-CD has been shown to have the highest affinity to cholesterol molecules compared to methyl- and hydrodypropyl-substituted $\beta$-CDs due to the absence of steric hindrance from the additional substituent groups typically incorporated to enhance solubility [26]. The conjugation of $\beta$-CD to hydrophilic AfFtnAA enhances its solubility and stability in aqueous solutions allowing the use of native $\mathrm{CDs}$. $\mathrm{M} \beta \mathrm{CD}$ is chosen for loading within the nanocage internal cavity and for in vitro cholesterol reduction assays due to its comparable cholesterol affinity and high aqueous solubility. A size increase from $5 \mathrm{~nm}$ for Apo-AfFtnAA to $12.5 \mathrm{~nm}$ for (Fe2400) AfFtnAA-CD is observed after conjugation and iron loading. Mass spectrometry measurements show the conjugation of AfFtnAA with the linker and subsequently with $\beta$-CD (Figs. 2(a) and 2(b)). Two significant peaks at 20.3 and $21.4 \mathrm{kDa}$ correspond to the expected molecular weight of AfFtnAA-PM and AfFtnAA-CD. Peak integration shows that $\sim 75 \%$ of the cysteines are modified corresponding to 17-18 molecules of cyclodextrin conjugated to each ferritin cage.

Encapsulation of CDs inside AfFtnAA is achieved by co-loading with its natural ligand. $\mathrm{Fe}^{2+}$ has been reported to drive the self-assembly of the AfFtnAA subunits during which other molecules could be encapsulated [27]. The encapsulation efficiency was quantified using

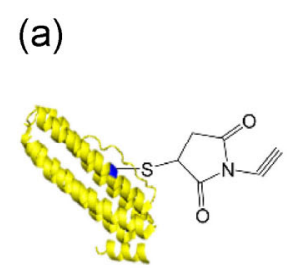

Apo AfFtnAA/E94C-PM

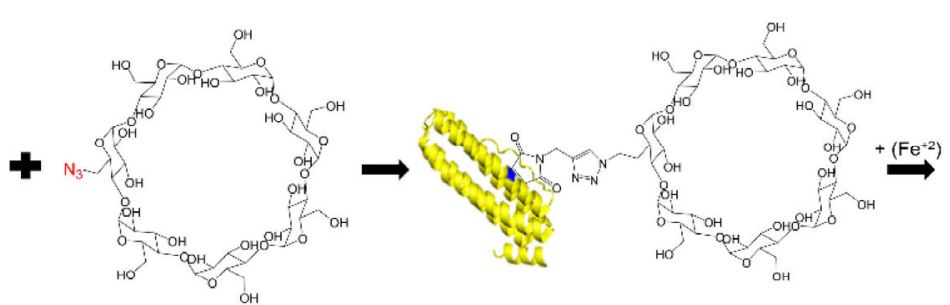

$\beta-C D-N_{3}$
Apo AfFtnAA-CD

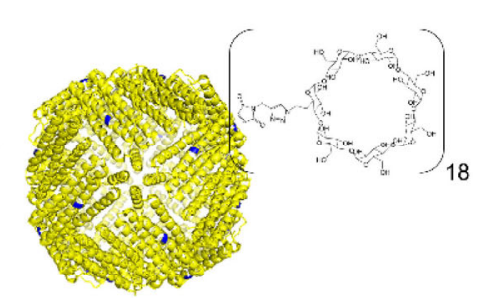

(Fe2400) AfFtnAA-CD nanocages

(b)

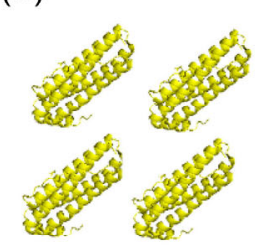

Apo AfFtnAA

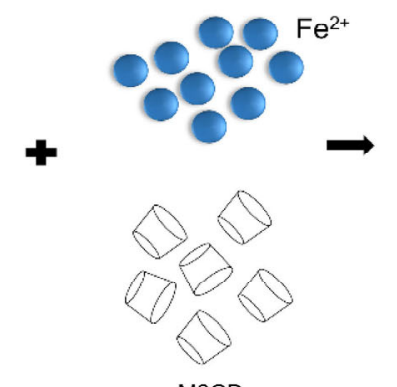

$\mathrm{M} \beta \mathrm{CD}$

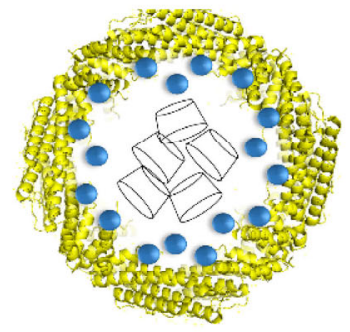

(Fe600) AfFtnAA (MBCD) nanocages

Figure 1 Display of cyclodextrin on the external surface and loading in the cavity of AfFtnAA. (a) Propargyl maleimide linker is reacted with the reduced cysteine groups on Apo-AfFtnAA following thiol-maleimide reaction chemistry. Linker conjugated protein subunits (Apo AfFtnAA/E94C-PM) are reacted with azide modified $\beta$-CD molecules in the presence of copper (II) sulphate as catalyst and sodium ascorbate as the reducing agent. Protein nanocages are assembled using the $\beta$-CD conjugated AfFtnAA sub-units (Apo AfFtnAA-CD) by the addition of 2,400 $\mathrm{Fe}^{2+}$ atoms to form the cyclodextrin-ferritin nanocage conjugates ((Fe2400) AfFtnAA-CD). (b) AfFtnAA subunits are assembled to form the nanocages following a co-loading method with 1,000 $\mathrm{M} \beta \mathrm{CD}$ molecules and 2,400 $\mathrm{Fe}^{2+}$ atoms incubated for a period of $1 \mathrm{~h}$ under static conditions to form the CD encapsulated AfFtnAA nanocages. 

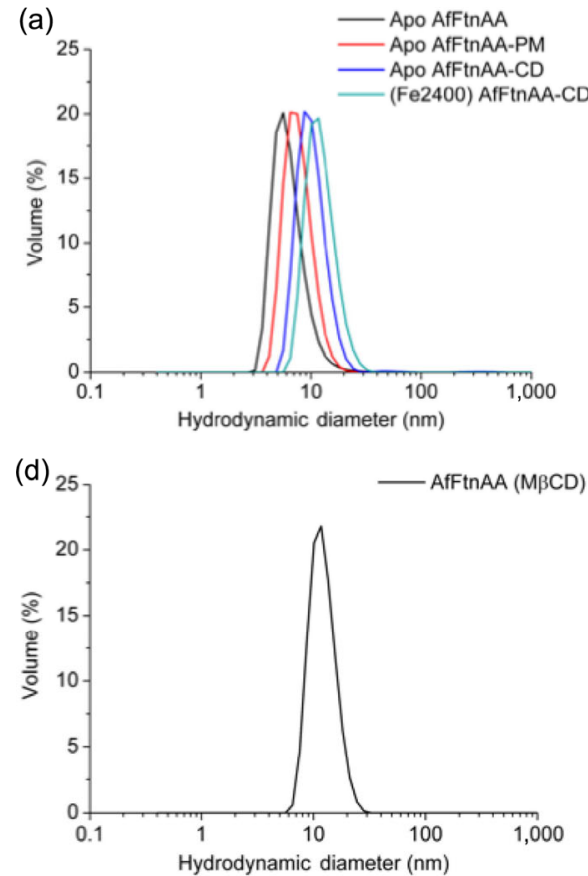

(b)

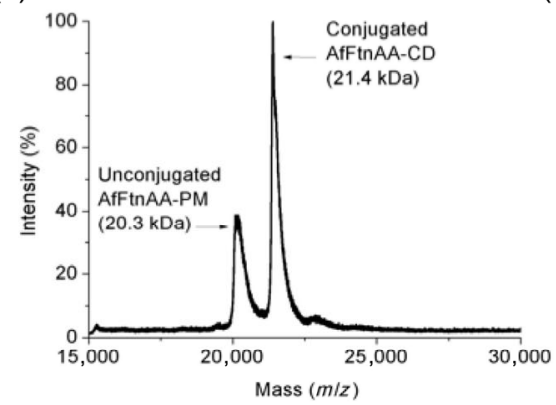

(e)

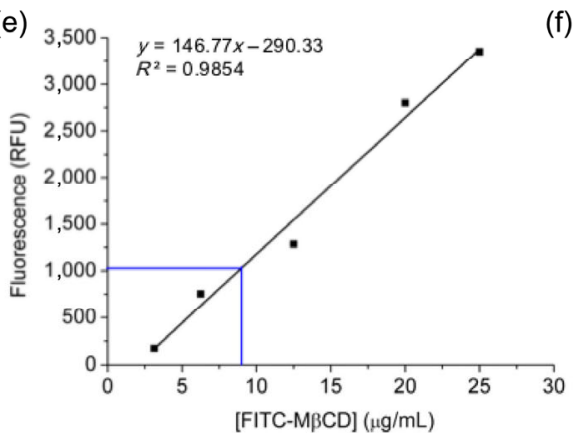

(c)

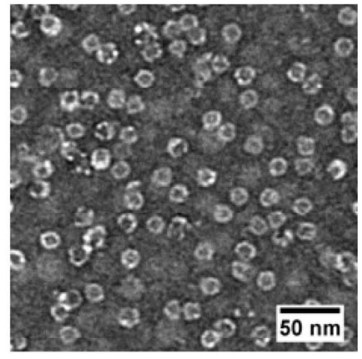

(f)

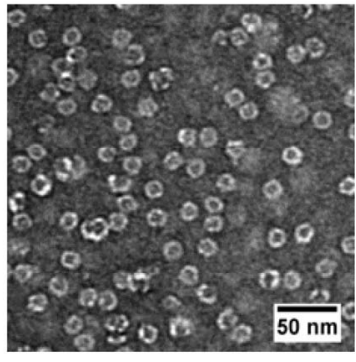

Figure 2 (a) Increase in size observed at individual reaction steps using DLS of Apo AfFtnAA, Apo AfFtnAA-PM, Apo AfFtnAA-CD and (Fe2400) AfFtnAA-CD nanocage. (b) Mass spectrometry graph of cyclodextrin conjugated nanocages with peaks corresponding to unconjugated AfFtnAA-PM and conjugated AfFtnAA-CD. (c) Electron micrograph of (Fe2400) AfFtnAA-CD. (d) DLS of AfFtnAA (M $\beta C D$ ) with hydrodynamic diameter at $13.5 \mathrm{~nm}$. (e) Standard curve of FITC-M $\beta C D$ with the position of AfFtnAA (FITC-M $\beta C D$ ) fluorescence indicated in blue. (f) Electron micrograph of AfFtnAA (M $\beta C D$ ).

fluorescence measurements of fluorescein isothiocyanate (FITC) tagged $\mathrm{M} \beta \mathrm{CD}$. The fluorescence measured from the ferritinencapsulated CD samples is correlated with a standard curve to estimate the amount of CD molecules loaded per cage (Fig. 2(e)). This yields a result of $\sim 35$ cyclodextrin molecules loaded in each ferritin nanocage.

Lastly, transmission electron microscopy (TEM) images of nanocages conjugated with and encapsulating cyclodextrin show intact cage structures thereby validating the retention of the self-assembly property of AfFtnAA post modifications with cyclodextrin molecules (Figs. 2(c) and $2(\mathrm{f}))$.

\subsection{Cholesterol binding affinity and intracellular cholesterol reduction studies}

Surface plasmon resonance approaches have been used to demonstrate high affinity of cyclodextrins to cholesterol molecules [28]. To ensure that cyclodextrin remains effective in binding cholesterol, their affinity has been determined using biolayer interferometry (BLI) with streptavidin-functionalized probe. Biolayer interferometry is a technique used to monitor interactions between molecules based on the interference pattern generated due to changes in optical thickness of the molecular layer caused by the binding of molecules to the probe $[29,30]$. After ensuring the absence of unspecific binding of AfFtnAA-CD to the streptavidin tip, biotinylated free cholesterol was immobilized onto the probe following high affinity streptavidin-biotin interactions. The relative ligand interaction of unconjugated and cyclodextrin-conjugated protein to the immobilized cholesterol molecules was studied (Fig. 3). Apo instead of iron-loaded AfFtnAA was used for the analysis due to the interference of metal ions with the BLI system. An increase in optical binding thickness is observed with CD conjugated protein. It is seen that the association rate of cyclodextrin conjugated was higher than the unconjugated protein indicating the role of cyclodextrin in increasing the affinity of AfFtnAA to the cholesterol molecule. Affinity measurements were conducted with varying concentrations of AfFtnAA-CD to determine the range of dissociation constant $\left(K_{\mathrm{D}}\right)$ values. Unconjugated
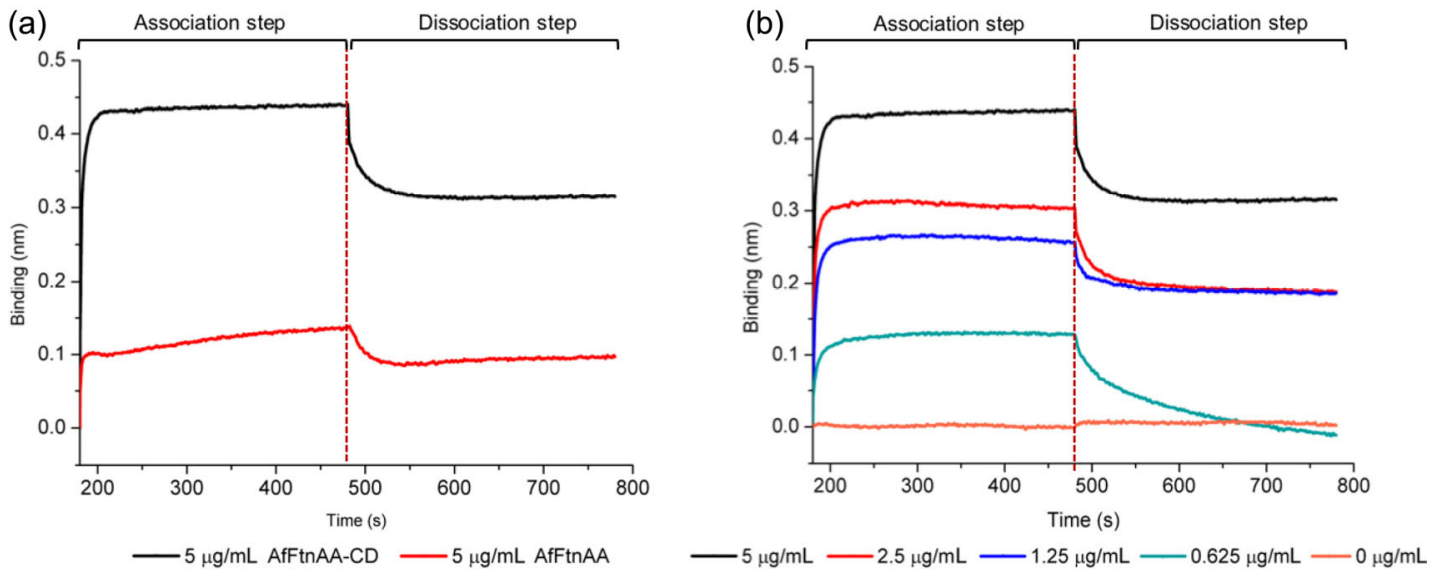

Figure 3 Biolayer interferometry results showing the binding affinity of (a) $5 \mu \mathrm{g} / \mathrm{mL}$ AfFtnAA, AfFtnAA-CD and (b) $0 \mu \mathrm{g} / \mathrm{mL}$ (water), $0.625,1.25,2.5,5 \mu \mathrm{g} / \mathrm{mL}$ AfFtnAA-CD to cholesterol immobilized on the streptavidin probe sensor. 
Apo AfFtnAA has a $K_{D}$ of $100 \mu \mathrm{M}$. In contrast, Apo AfFtnAA-CD shows higher specific binding towards free cholesterol with a $K_{\mathrm{D}}$ of $\sim$ $5 \mathrm{nM}$. Interactions between $\mathrm{M} \beta \mathrm{CD}$ were not quantified due to the limitation of the instrument being unable to measure small molecular (less than $10 \mathrm{kDa}$ ) interactions. These results confirm the functionality of cyclodextrin upon conjugation with AfFtnAA and suggest its usage for cholesterol sequestration in physiological systems.

Upon confirmation of molecular binding of AfFtnAA-CD to cholesterol molecules using interferometry, the cholesterol sequestration capacity of AfFtnAA-CD was tested in vitro. Foam cells generated by incubation with $40 \mu \mathrm{g} / \mathrm{mL}$ oxidized low-density lipoproteins (oxLDL) under serum free media conditions showed intracellular cholesterol accumulation. Amplex red assay was used as a quantitative assay to measure cholesterol reduction in foam cells treated with the different conditions for $24 \mathrm{~h}$. Macrophage cells without oxLDL treatment and untreated foam cells were used as controls. A 38\% reduction in accumulated intracellular cholesterol was observed with AfFtnAA-CD treatment which was comparable to cholesterol levels in macrophage cells (Fig. 4(a)). AfFtnAA loaded with $\mathrm{M} \beta \mathrm{CD}$ showed a decrease in accumulated cholesterol levels. However, a more significant decrease was observed with AfFtnAA-CD treatment. Cells treated with native AfFtnAA did not show any marked decrease in \% of accumulated cholesterol as compared to the untreated samples.

The effect of AfFtnAA-CD was further tested with treatment in a time dependent manner varying from 1 to $24 \mathrm{~h}$ (Fig. 4(b)). We found a decrease in cholesterol levels within 2 to $6 \mathrm{~h}$ of treatment with AfFtnAA-CD. The results validate that the CD remained functional upon conjugation and mediated cholesterol sequestration property of AfFtnAA-CD. The overall cholesterol levels of treated cells dropped to the level of untreated macrophage cells within $6 \mathrm{~h}$ of treatment thereby, highlighting the effectiveness of AfFtnAA-CD in reducing intracellular cholesterol level.

\subsection{Preferential accumulation of ferritin in foam cells}

To gain an insight into the uptake specificity of AfFtnAA and FITC-M $\beta C D$ to foam cells over macrophage cells, quantitative uptake tests were carried out using ICP-MS and imaged using fluorescence microscopy. Utilizing the presence of iron atoms within ferritin nanocages, quantification of total iron content inside cells using ICP-MS was used as a method to monitor cellular uptake levels of AfFtnAA (Fig. 5(a)). The iron concentrations are normalized against cell number to obtain the relative amount of iron per cell thus correlating with the relative AfFtnAA accumulated per cell. Over increasing duration of treatment, a steady increase in accumulated iron content is observed with foam cells demonstrating greater uptake relative to macrophage cells. After $24 \mathrm{~h}$, foam cells show almost triple increase in uptake of AfFtnAA as compared to unloaded macrophage cells. The increased uptake levels in foam cells are also visualized using fluorescence imaging (Fig. 5(b)). A similar increase in uptake of protein conjugates is observed in macrophage cells and foam cells treated with AfFtnAA-CD for a duration of $24 \mathrm{~h}$ (Fig. 5(c)).

Human ferritin undergoes transferrin receptor mediated endocytosis in mitogen activated $\mathrm{T}$ and $\mathrm{B}$ cells [31]. A co-incubation test with transferrin, a natural ligand of transferrin receptor, is conducted to further confirm a similar uptake mechanism in macrophage cells incubated with the ferritin cages studied here. As expected, accumulated iron amounts in cells incubated only with transferrin is found to be lower than when incubated with AfFtnAA. This is due to the lower iron content of $10 \mathrm{Fe}$ atoms per molecule of transferrin as compared to AfFtnAA with 1,700 Fe atoms per cage. Normalization with the $\mathrm{Fe}$ atoms per cage shows up to 3 times higher uptake of transferrin than ferritin thus validating it as a natural ligand. Co-incubation of 5 times (by mass) higher amount of transferrin with AfFtnAA results in only a slight increase in total cellular iron content, thus, indicating the inhibition effect on ferritin uptake as a result of co-incubation. The transferrin uptake serves as the baseline for subsequent calculations. Subtraction of iron content due to transferrin uptake from the total intracellular iron measured after co-incubation shows a $62 \%$ inhibition in AfFtnAA uptake (Fig. 5(d)). The decrease in uptake in the presence of transferrin is also visualized using fluorescence imaging of AfFtnAA tagged with AlexaFluor 488 in the inner cage surface (Fig. S2 in the ESM). We observe an inhibition of AfFtnAA uptake in the presence of excess transferrin thereby suggesting the role of transferrin receptor mediated endocytosis pathway in ferritin uptake.

The absence on metal ions from cyclodextrin cavity requires an alternative method to monitor the intracellular iron levels. Fluorescence imaging has been used to observe the localization of FITC conjugated M $\beta C D$ in macrophage and foam cells at 2 and $24 \mathrm{~h}$ time points (Figs. 6(a) and 6(b)). The values have been corrected for any autofluorescence observed in untreated cells. Increase in fluorescence intensities are observed after $24 \mathrm{~h}$ as compared to a $2 \mathrm{~h}$ treatment period for both macrophage and foam cells. However, no significant difference is observed between the fluorescence intensities in the two cell types for each of the time points measured.
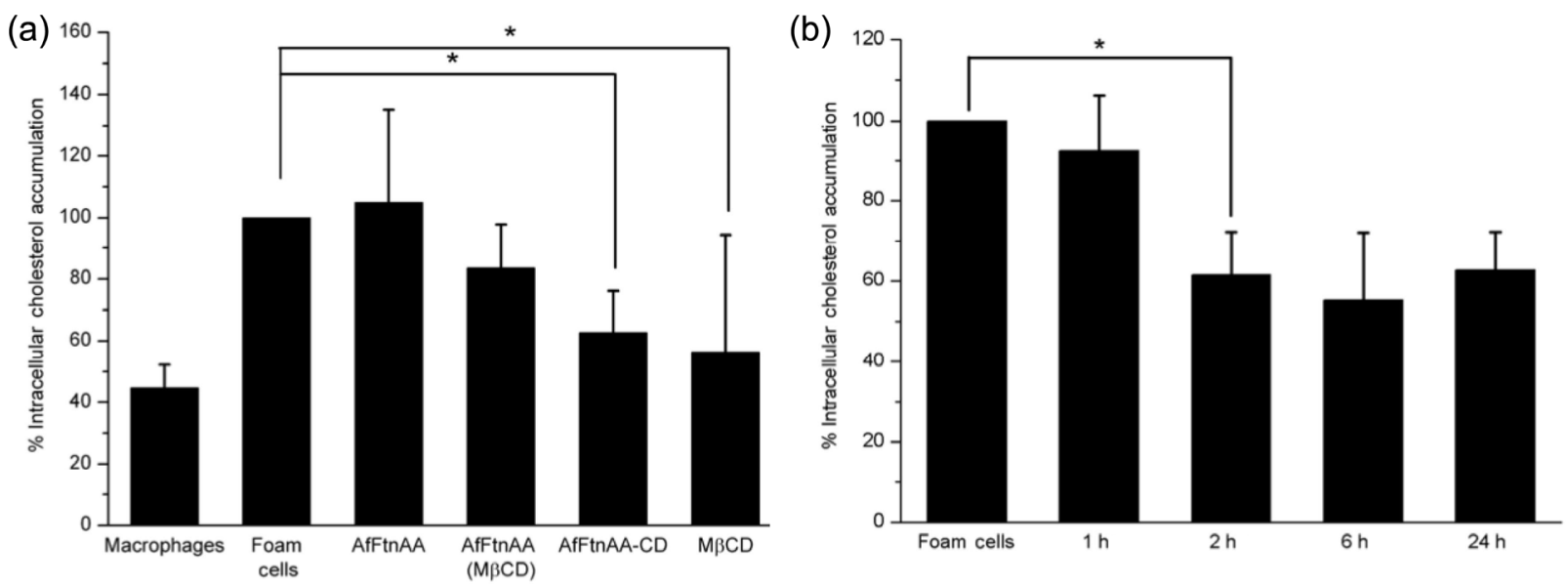

Figure 4 (a) Quantification of intracellular cholesterol accumulation in foam cells treated with $130 \mu \mathrm{g} / \mathrm{mL}$ AfFtnAA, $65 \mu \mathrm{g} / \mathrm{mL}$ AfFtnAA (MßCD), $130 \mu \mathrm{g} / \mathrm{mL}$ AfFtnAA-CD using Amplex Red cholesterol assay. Cholesterol amounts per $\mu \mathrm{g}$ of cell protein has been normalized with untreated cells to obtain the $\%$ of accumulated intracellular cholesterol. (b) Intracellular cholesterol reduction upon treatment with $130 \mu \mathrm{g} / \mathrm{mL}$ AfFtnAA-CD for varying treatment durations of $1,2,6$ and $24 \mathrm{~h}$. \pm SEM. ( $n=2$, where $n$ is the least number of independent experiments performed in triplicate). Statistical analysis has been performed using one-way analysis of variance (ANOVA) test. ${ }^{*} P<0.05$. 


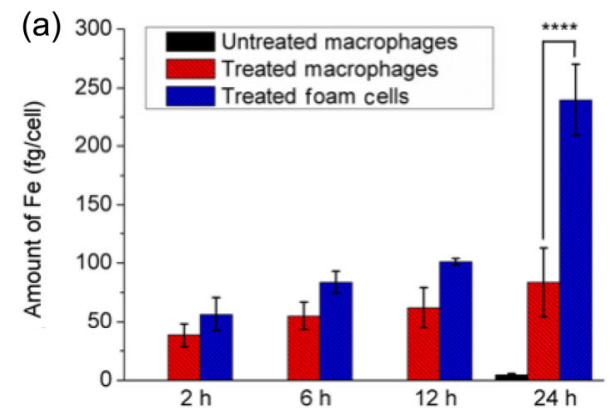

(b)

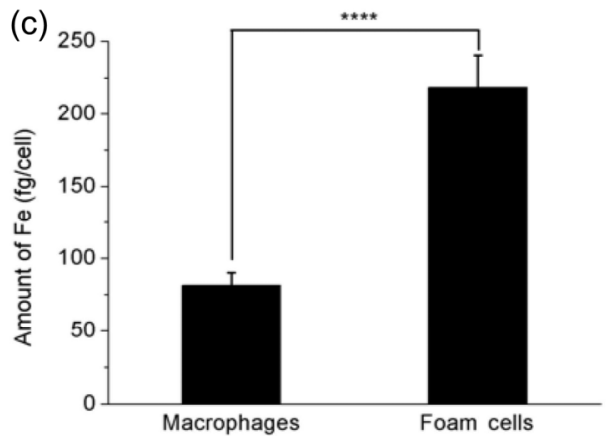

(d)
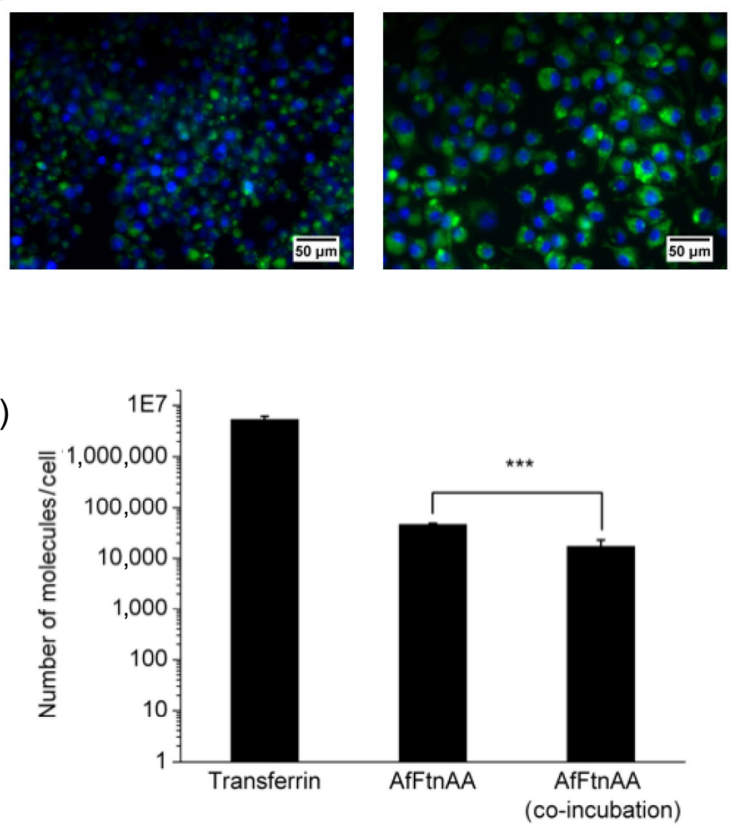

Figure 5 Cellular uptake of AfFtnAA and AfFtnAA-CD. (a) Quantification of cellular uptake of macrophage cells and foam cells treated with $130 \mu \mathrm{g} / \mathrm{mL}$ AfFtnAA for 2, 6, 12 and $24 \mathrm{~h}$. Macrophage cells without incubation with AfFtnAA are used as control. (b) Uptake study using dye conjugated ferritin nanocages (AfFtnAA-AF488) incubated with RAW264.7 macrophage cells and foam cells for $24 \mathrm{~h}$. In conjunction with the ICP-MS results, increased fluorescence intensity is observed per cell for foam cells incubated with the cages as compared to macrophage cells. (c) Cellular uptake of $130 \mu \mathrm{g} / \mathrm{mL}$ AfFtnAA-CD quantified using ICP-MS with cells treated for $24 \mathrm{~h} \pm \mathrm{SD}$. (d) Identification of transferrin receptor as a receptor for uptake of AfFtnAA. Cells were incubated with $325 \mu \mathrm{g} / \mathrm{mL}$ transferrin, $65 \mu \mathrm{g} / \mathrm{mL} \mathrm{AfFtnAA}$ and co-incubation of the same concentration of transferrin and AfFtnAA for $90 \mathrm{~min}$. Iron content inside the cells was quantified using ICP-MS and normalized with iron content per molecule to correlate with protein uptake and inhibition. Statistical analysis has been performed using one-way ANOVA test ( $n=3$, where $n$ is the number of independent experiments with triplicate measurements taken for each). ${ }^{* * *} P<0.005$ and ${ }^{* * * *} P<0.001$.
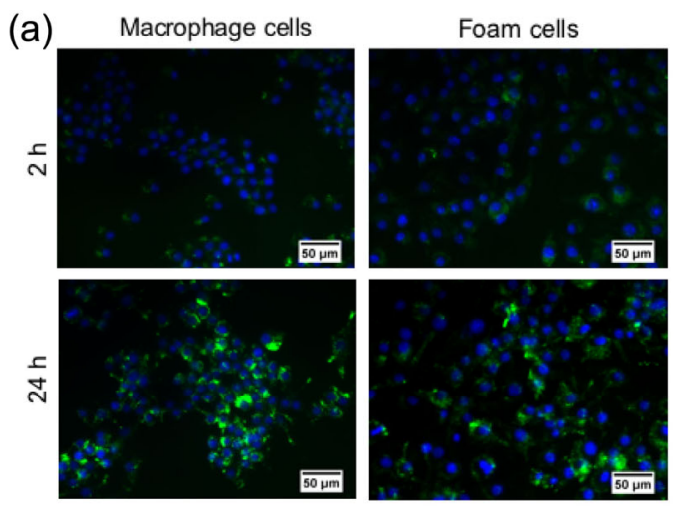

(b)

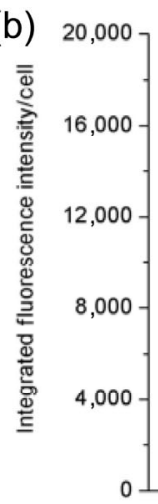

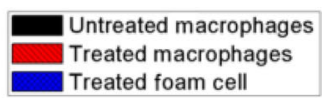

Treated foam cell

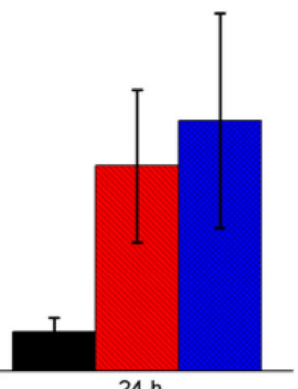

Figure 6 Cellular uptake of FITC-M $\beta C D$. (a) Fluorescence images of macrophage and foam cells incubated with $1 \mathrm{mM}$ FITC-M $\beta C D$ for 2 and 24 h. (b) Quantification of fluorescence intensities normalized with cell number per frame. \pm SD for all quantified images $(n=3$, where $n$ is the number of experiments performed). Statistical analysis has been performed using one-way ANOVA test.

\section{Discussion}

In this work, we compare the cholesterol sequestration capacity of ferritin nanocages that have been modified with $\beta$-cyclodextrin both on the internal and external cage surface. We have demonstrated similar cholesterol sequestration efficacy of conventional atherosclerosis first-line drug, simvastatin, and $\mathrm{M} \beta \mathrm{CD}$ molecules using the foam cell models developed for this work (Fig. S3 in the ESM). Eighteen molecules of cyclodextrin were conjugated to the cage using CuAAC reaction. Previous studies using CuAAC reaction method makes use of long linkers such as N-propargyl-3-maleimidopropionamide as an alternative to the propargyl maleimide linker used in this study [32]. Although resulting in slightly enhanced conjugation efficiency, additional reaction steps for synthesis of the long linker can be avoided while maintaining at least $75 \%$ conjugation using propargyl maleimide. Approximately 35 molecules of $\mathrm{M} \beta \mathrm{CD}$ were encapsulated within the cage cavity following the co-loading method with metal ions. This corresponds to a loading capacity of $11.7 \%$ which resulted in higher number of cyclodextrin molecules per cage in comparison to external surface conjugation. In addition to the metal-induced assembly, AfFtnAA comprises of hydrophobic residues on the inner surface which could further contribute to the encapsulation affinity of CDs.

We have shown intracellular cholesterol reduction using both AfFtnAA (MBCD) and AfFtnAA-CD with a greater reduction occurring upon treatment with the latter. Recent studies have demonstrated prolonged CD mediated cholesterol efflux after endocytosis by Niemann Pick Type C mutant cells, a disorder characterized by the accumulation of lysosomal cholesterol [33]. The comparison between AfFtnAA-CD and AfFtnAA (M $\beta C D)$ in mediating intracellular cholesterol reduction highlights the dual importance of cell membrane interaction of CDs obtained from the 
conjugated nanocages along with possible interactions with the intracellular cholesterol pool after endocytosis of the conjugates.

A $62 \%$ inhibition in AfFtnAA uptake in macrophage cells is observed upon co-incubation with 5 times molar excess of transferrin. The data suggest that endocytosis of ferritin in macrophage cells is most likely mediated by transferrin receptors which are known to be overexpressed in human carotid plaque foam cells [34]. Therefore, ferritin can serve as a useful delivery platform owing to its passive uptake property and preferential localization in foam cells overexpressing the receptor of interest.

Unlike the receptor mediated endocytosis pathway of AfFtnAA, uptake of FITC-M $\beta C D$ has been shown to be mediated via micropinocytosis pathway in Caco cells [35]. This pathway, also known as cell drinking, does not involve receptors specific to the ligand (CDs in this case) and results in uptake of the ligands along with other extracellular matrix proteins. Since this pathway is common to both foam cells and macrophage cells, no appreciable difference in FITC-M $\beta C D$ uptake is observed between the two cell types as we have shown using fluorescence imaging.

The high dosage requirement of CDs has limited its clinical translation as a bare drug despite its high cholesterol affinity. This could be explained by the $<1 \mathrm{~nm}$ size of CD molecules. CD half-life $\left(t_{1 / 2}\right)$ is estimated to be less than $2 \mathrm{~h}$ and is expected to be cleared from the system within $6 \mathrm{~h}$ [36]. CDs administered through intravenous injection are rapidly cleared by the kidneys preventing them from permeating and localizing in foam cells in lesion sites. The passive accumulation property of ferritin in foam cells demonstrated in this work suggests that protein cages could act as mediators of specific delivery of CDs to foam cells. This could result in enhanced localization of CDs in the plaque region in vivo, thus potentially reducing $\mathrm{CD}$ dosage requirements to below sub-toxic levels.

\section{Conclusions}

Foam cells in atherosclerosis have been identified as key targets to mediate atherosclerosis regression by facilitating a reduction in intracellular accumulated cholesterol. In previous works, ferritin protein nanocages have been proposed to be used as contrast agents due to EPR mediated preferential accumulation property in the plaque region. We report the use of cyclodextrin conjugated ferritin nanocages as a therapeutic molecules to reduce cholesterol from foam cells. We demonstrate high affinity of cyclodextrin-ferritin conjugate to cholesterol molecules and subsequently observed cholesterol reduction in in vitro foam cell models. Furthermore, ferritin has been shown to accumulate in foam cells with 3 -folds higher quantity than in macrophage cells thus demonstrating preference. Our study opens perspectives on harnessing the potential of ferritin nanocages as a versatile platform for atherosclerosis diagnosis and therapy.

\section{Experimental}

\subsection{AfFtnAA modification and production}

Cysteine substitution was made at position 94 in the AfFtnAA gene and was verified to be located on the outer cage surface using PyMol simulations. The $94^{\text {th }}$ amino acid residue is a non-interacting residue on the external surface of ferritin avoiding any steric hindrance with the ferroxidase sites of the cages. The substitution on AfFtnAA gene is carried out using site directed mutagenesis following protocols mentioned by Bachman [37]. Briefly, forward and reverse primers are designed to include the codons corresponding to the mutation with $\sim 30$ amino acid extensions binding to AfFtnAA (template) plasmid. The linear amplification of the plasmid is carried out for a total of 40 cycles and a final extension of $15 \mathrm{~min}$. The template plasmids were digested with Dpn1 and transformed into E. coli DH5a competent cells for colony screening. The isolated plasmid was then transformed into a E. coli BL21(DE3)-C+RIL strain and overexpressed in lysogeny broth (LB) medium containing ampicillin $(100 \mu \mathrm{g} / \mathrm{mL})$ and chloramphenicol $(50 \mu \mathrm{g} / \mathrm{mL})$. The overexpression and protein purification was performed as previously described $[16,19]$. Optical density (OD) measurements were taken during cell growth. Gene expression was induced by the addition of $1 \mathrm{mM}$ isopropyl $\beta$-Dthiogalactopyranoside (IPTG) when $\mathrm{OD}_{600}$ reached between 0.6 and 0.8 . Post $4 \mathrm{~h}$ of growth after induction the cells were harvested using a centrifuge at $8,000 \mathrm{~g}$ for $5 \mathrm{~min}$. Cell pellets were then lysed using a ultrasonicator followed by heat treatment at $85{ }^{\circ} \mathrm{C}$ for $10 \mathrm{~min}$. Hydrophobic interaction chromatography (HIC) was performed on a AKTA-Explorer FPLC System (GE Healthcare) using a HiPrep Phenyl FF (high sub) column equilibrated with $25 \mathrm{mM}$ 4-(2-hydroxyethyl)-1piperazineethanesulfonic acid (HEPES), $50 \mathrm{mM} \mathrm{NaCl}$ and $500 \mathrm{mM}$ $\left(\mathrm{NH}_{4}\right)_{2} \mathrm{SO}_{4}$ buffer at $\mathrm{pH}$ 7.4. The desired protein was eluted out of the column with $25 \mathrm{mM}$ HEPES, $50 \mathrm{mM} \mathrm{NaCl}$. The eluted proteins were buffer exchanged with $25 \mathrm{mM}$ HEPES, $50 \mathrm{mM} \mathrm{NaCl}, \mathrm{pH} 7.4$ buffers using a Amicon Ultra-15 Centrifugal Filter Units (10,000 Da) to remove any $\left(\mathrm{NH}_{4}\right)_{2} \mathrm{SO}_{4}$ present in the eluted fractions. Protein concentrations were measured using Bradford Assay with bovine serum albumin (BSA) as the standard and the Quick Start ${ }^{\mathrm{TM}}$ Bradford 1X Dye Reagent.

\subsection{Conjugation of cyclodextrin}

Cyclodextrin was conjugated to the protein cage using copper (I) catalysed azide/alkyne cycloaddtion reaction (CuAAC) following the methods described previously with slight modifications [32]. Cysteine mutations on the cage was reduced by the addition of 15 molar excess of tris(2-carboxyethyl)phosphine (TCEP) and incubated for $1 \mathrm{~h}$ at room temperature (RT) on a 3D shaker. Propargyl maleimide ( $M_{\mathrm{W}} \sim 130.12 \mathrm{Da}$, Kerafast, Inc., USA) was used as the linker to react with the sulphydyl groups of the cysteine. AfFtnAA was incubated with 100 molar equivalents of propargyl maleimide for $3 \mathrm{~h}$ at $25^{\circ} \mathrm{C}$ with vigorous shaking at $200 \mathrm{rpm}$. Unreacted propargyl malemide was then removed using a PD-10 column using $25 \mathrm{mM}$ HEPES, $50 \mathrm{mM} \mathrm{NaCl}, \mathrm{pH} 7.4$ as the buffer. The $\mathrm{CuAAC}$ reaction was then performed using $10 \mu \mathrm{M}$ of AfFtnAA-PM, $15 \mathrm{mM}$ 6-Monodeoxy-6-monoazido-beta-cyclodextrin $\left(M_{\mathrm{w}} \sim 1,160 \mathrm{Da}\right.$, CycloLab Ltd., Hungary), $0.25 \mathrm{mM}$ copper (II) sulphate, $2.5 \mathrm{mM}$ tris(3-hydroxypropyltriazolylmethyl)amine, $5 \mathrm{mM}$ sodium ascorbate and $5 \mathrm{mM}$ aminoguanidine hydrochloride (Sigma) incubated at $25{ }^{\circ} \mathrm{C}$ for $12 \mathrm{~h}$. Unreacted components were then removed using a PD-10 column and desalted AfFtnAA-CD stored in $4{ }^{\circ} \mathrm{C}$ for further characterization.

\subsection{Loading of cyclodextrin}

Equivalent of 1,000 atoms of fluorescently labelled randomly $\mathrm{M} \beta \mathrm{CD}$ (FITC-M $\beta C D)\left(M_{\mathrm{W}} \sim 1,300 \mathrm{Da}\right.$, CycloLab Ltd., Hungary) and 600 $\mathrm{Fe}$ atoms per ferritin cage was co-loaded at RT and incubated for $2 \mathrm{~h}$. Excess FITC-M $\beta C D$ was desalted using a PD-10 column. The number of FITC-M $\beta C D$ molecules encapsulated was characterized by fluorescence measurements at Ex495/Em519 nm and correlated with a standard curve plotted with known concentrations of FITC-M $\beta$ CD.

\subsection{Protein size determination}

The hydrodynamic size of the protein was determined by dynamic light scattering (DLS) (Zetasizer Malvern Instruments) by assaying a $0.2 \mathrm{mg} / \mathrm{mL}$ protein sample in $25 \mathrm{mM}$ HEPES, $50 \mathrm{mM} \mathrm{NaCl}, \mathrm{pH}$ 7.4. The intact assembly of the protein nanocages after conjugation with cyclodextrin was confirmed using TEM (JEOL JEM1400). Samples of $0.1 \mathrm{mg} / \mathrm{mL}$ were stained with $2 \%$ uranyl acetate and imaged at $100 \mathrm{kV}$ and 25,000 $\times$ magnification. 


\subsection{Biolayer interferometry}

The interactions between AfFtn-CD and unesterified cholesterol molecules were measured by biolayer interferometry using the ForteBio BLItz unit. Before the experiment, streptavidin biosensors (Fortebio) was hydrated in MiliQ water for $10 \mathrm{~min}$. CholesterolPEG-Biotin ( $M_{\mathrm{W}} \sim 5,000 \mathrm{Da}$, NanoCS) at $100 \mu \mathrm{g} / \mathrm{mL}$ was immobilized onto the streptavidin probe for $150 \mathrm{~s}$ and the baseline was generated in MiliQ water for $30 \mathrm{~s}$. The probe was dipped in varying concentrations of the protein followed by MiliQ water during the association and dissociation step respectively for $300 \mathrm{~s}$ each. The binding of AfFtnAA to the probe without immobilized cholesterol molecule was also tested as a negative control. The dissociation constants were then calculated using the BLItz Pro $^{\mathrm{TM}}$ software.

\subsection{Foam cell formation}

RAW 264.7 murine macrophage cells were cultured in Dulbeco's modified Eagle's medium (DMEM), 10\% foetal bovine serum (FBS) and $1 \%$ penicillin-streptomycin media (all from Gibco ${ }^{\mathrm{TM}}$ ) in T-75 flasks. Cells at 20,000 were seeded in 96 well plates and grown overnight in $37^{\circ} \mathrm{C}$. The medium was then changed to a serum free media for $12 \mathrm{~h}$ followed by $24 \mathrm{~h}$ incubation with $40 \mu \mathrm{g} / \mathrm{mL}$ oxidized low density lipoprotein (oxLDL). oxLDL was synthesized by the oxidation of low density lipoprotein (LDL) (Lee Biosolutions, USA) with $5 \mu \mathrm{M}$ of $\mathrm{CuSO}_{4}$ in phosphate buffer saline (PBS) for $16 \mathrm{~h}$ at $37^{\circ} \mathrm{C}$.

\subsection{Cell staining and imaging}

Cells were fixed with $4 \%$ paraformaldehyde (Sigma) by incubation in $4{ }^{\circ} \mathrm{C}$ for $15 \mathrm{~min}$. After washing with PBS, cells were incubated with 4',6-diamidino-2-phenylindole (DAPI, Thermo Fisher Scientific) for $30 \mathrm{~min}$ at $37^{\circ} \mathrm{C}$ in darkness. The cells were then washed with PBS and imaged using an inverted Zeiss Axiovert S100 fluorescence microscope (Carl Zeiss, Germany) with a $20 \times$ objective at excitation wavelength of $405 \mathrm{~nm}$ and $488 \mathrm{~nm}$ for DAPI stained and AF488 conjugated samples, respectively. Fluorescence imaging of other samples including cells incubated with both FITC-MBCD and dye conjugated AfFtnAA were imaged using the same equipment parameters.

\subsection{Uptake study using ICP-MS}

Cells were seeded in 24 well plates at a seeding density of $0.1 \times$ $10^{6}$ cells $/ \mathrm{mL}$. Some wells were incubated with oxLDL to form foam cells following the protocol mentioned earlier. Post incubation with AfFtnAA for varying time points (2, 6 and $24 \mathrm{~h}$ ), cells were scraped and resuspended in $250 \mu \mathrm{L}$ of PBS. An aliquot of $20 \mu \mathrm{L}$ was used for cell counting and the rest was digested with nitric acid to prepare samples for ICP-MS analysis.

\subsection{Cholesterol enzymatic assay}

Cholesterol was extracted from the cells using hexane:isopropanol $(3: 2, \mathrm{v} / \mathrm{v})$ solution by incubation at RT for $1 \mathrm{~h}$. Enzymatic assay was conducted using Amplex Red Cholesterol Assay kit (Thermo Fisher Scientific) following the protocol provided by the supplier. Briefly, samples were diluted with the reaction buffer and incubated with $0.2 \mathrm{U} / \mathrm{mL}$ cholesterol esterase, $2 \mathrm{U} / \mathrm{mL}$ cholesterol oxidase, $2 \mathrm{U} / \mathrm{mL}$ horseradish peroxidase and $300 \mu \mathrm{M}$ Amplex Red for $1 \mathrm{~h}$ at $37^{\circ} \mathrm{C}$. Fluorescence was measured at Ex560/Em590nm. Cell protein from the cells was extracted using $0.2 \mathrm{M} \mathrm{NaOH}$ and quantified using Bradford assay.

\section{Acknowledgements}

This work was support by NTU-Northwestern Institute for Nanomedicine grant (No. M4081504.F40.706022).
Electronic Supplementary Material: Supplementary material (including further details of protein characterization, ICP-MS, fluorescence, intracellular cholesterol measurements) is available in the online version of this article at https://doi.org/10.1007/s12274019-2525-2.

Open Access This article is licensed under a Creative Commons Attribution 4.0 International License, which permits use, sharing, adaptation, distribution and reproduction in any medium or format, as long as you give appropriate credit to the original author(s) and the source, provide a link to the Creative Commons licence, and indicate if changes were made.

The images or other third party material in this article are included in the article's Creative Commons licence, unless indicated otherwise in a credit line to the material. If material is not included in the article's Creative Commons licence and your intended use is not permitted by statutory regulation or exceeds the permitted use, you will need to obtain permission directly from the copyright holder.

To view a copy of this licence, visit http://creativecommons.org/licenses/by/4.0/.

\section{References}

[1] Barquera, S.; Pedroza-Tobias, A.; Medina, C.; Hernández-Barrera, C.; Bibbins-Domingo, K.; Lozano, R.; Moran, A. E. Global overview of the epidemiology of atherosclerotic cardiovascular disease. Arch Med. Res. 2015, 46, 328-338.

[2] Bittencourt, M. S.; Cerci, R. J. Statin effects on atherosclerotic plaques: Regression or healing? BMC Med. 2015, 13, 260.

[3] Pankajakshan, D.; Agrawal, D. K. Clinical and translational challenges in gene therapy of cardiovascular diseases. In Gene Therapy-Tools and Potential Applications, USA, 2013, pp 651-683.

[4] Angelovich, T. A.; Hearps, A. C.; Jaworowski, A. Inflammation-induced foam cell formation in chronic inflammatory disease. Immunol. Cell Biol. 2015, 93, 683-693.

[5] Llodrá, J.; Angeli, V.; Liu, J. H.; Trogan, E.; Fisher, E. A.; Randolph, G. J. Emigration of monocyte-derived cells from atherosclerotic lesions characterizes regressive, but not progressive, plaques. Proc. Natl. Acad. Sci. USA 2004, 101, 11779-11784.

[6] Bäck, M.; Hansson, G. K. Anti-inflammatory therapies for atherosclerosis. Nat. Rev.Cardiol. 2015, 12, 199-211.

[7] Blanco, H.; Shen, M. F.; Ferrari. M. Principles of nanoparticle design for overcoming biological barriers to drug delivery. Nat. Biotechnol. 2015, 33, 941-951.

[8] Sanchez-Gaytan, B. L.; Fay, F.; Lobatto, M. E.; Tang, J.; Ouimet, M.; Kim, Y.; van der Staay, S. E.; van Rijs, S. M.; Priem, B.; Zhang, L. et al. HDL-mimetic PLGA nanoparticle to target atherosclerosis plaque macrophages. Bioconjugate Chem. 2015, 26, 443-451.

[9] Marrache, S.; Dhar, S. Biodegradable synthetic high-density lipoprotein nanoparticles for atherosclerosis. Proc. Natl. Acad. Sci. USA 2013, 110, 9445-9450.

[10] Niyonzima, N.; Samstad, E. O.; Aune, M. H.; Ryan, L.; Bakke, S. S.; Rokstad, A. M.; Wright, S. D.; Damås, J. K.; Mollnes, T. E.; Latz, E. et al. Reconstituted high-density lipoprotein attenuates cholesterol crystal-induced inflammatory responses by reducing complement activation. J. Immunol. 2015, 195, 257-264.

[11] Gu, X.; Zhang, W. L.; Liu, J. P.; Shaw, J. P.; Shen, Y. J.; Xu, Y. M.; Lu, H.; $\mathrm{Wu}, \mathrm{Z}$. M. Preparation and characterization of a lovastatin-loaded proteinfree nanostructured lipid carrier resembling high-density lipoprotein and evaluation of its targeting to foam cells. AAPS PharmSciTech 2011, 12, $1200-1208$.

[12] Spicer, C. D.; Jumeaux, C.; Gupta, B.; Stevens, M. M. Peptide and protein nanoparticle conjugates: Versatile platforms for biomedical applications. Chem. Soc. Rev. 2018, 47, 3574-3620.

[13] Kitagawa, T.; Kosuge, H.; Uchida, M.; Dua, M. M.; Iida, Y.; Dalman, R. L.; Douglas, T.; McConnell, M. V. RGD-conjugated human ferritin nanoparticles for imaging vascular inflammation and angiogenesis in experimental carotid and aortic disease. Mol. Imaging Biol. 2012, 14, 315-324. 
[14] Lobatto, M. E.; Calcagno, C.; Millon, A.; Senders, M. L.; Fay, F.; Robson, P. M.; Ramachandran, S.; Binderup, T.; Paridaans, M. P. M.; Sensarn, S. et al. Atherosclerotic plaque targeting mechanism of long-circulating nanoparticles established by multimodal imaging. ACS Nano 2015, 9, 1837-1847.

[15] Terashima, M.; Uchida, M.; Kosuge, H.; Tsao, P. S.; Young, M. J.; Conolly, S. M.; Douglas, T.; McConnell, M. V. Human ferritin cages for imaging vascular macrophages. Biomaterials 2011, 32, 1430-1437.

[16] Nandwana, V.; Ryoo, S. R.; Kanthala, S.; Kumar, A.; Sharma, A.; Castro, F. C.; Li, Y.; Hoffman, B.; Lim, S.; Dravid, V. P. Engineered ferritin nanocages as natural contrast agents in magnetic resonance imaging. $R S C$ Adv. 2017, 7, 34892-34900.

[17] Sana, B.; Johnson, E.; Sheah, K; Poh, C. L.; Lim, S. Iron-based ferritin nanocore as a contrast agent. Biointerphases 2010, 5, FA48.

[18] Sana, B.; Poh, C. L.; Lim, S. A manganese-ferritin nanocomposite as an ultrasensitive $T_{2}$ contrast agent. Chem. Commun. 2012, 48, 862-864.

[19] Sana, B.; Johnson, E.; Le Magueres, P.; Criswell, A.; Cascio, D.; Lim, S. The role of nonconserved residues of Archaeoglobus fulgidus ferritin on its unique structure and biophysical properties. J. Biol. Chem. 2013, 288 , 32663-32672.

[20] Bhaskar, S.; Lim, S. Engineering protein nanocages as carriers for biomedical applications. NPG Asia Materials 2017, 9, e371.

[21] Liu, S. M.; Cogny, A.; Kockx, M.; Dean, R. T.; Gaus, K.; Jessup, W.; Kritharides, L. Cyclodextrins differentially mobilize free and esterified cholesterol from primary human foam cell macrophages. J. Lipid Res. 2003, 44, 1156-1166.

[22] Atger, V. M.; de la Llera Moya, M.; Stoudt, G. W.; Rodrigueza, W. V.; Phillips, M. C.; Rothblat, G. H. Cyclodextrins as catalysts for the removal of cholesterol from macrophage foam cells. J. Clin. Invest. 1997, 99, 773-780.

[23] Loftsson, T.; Jarho, P.; Másson, M.; Järvinen, T. Cyclodextrins in drug delivery. Expert Opin. Drug Deliv. 2005, 2, 335-351.

[24] Davis, M. E.; Brewster, M. E. Cyclodextrin-based pharmaceutics: Past, present and future. Nat. Rev. Drug Discov. 2004, 3, 1023-1035.

[25] Zimmer, S.; Grebe, A.; Bakke, S. S.; Bode, N.; Halvorsen, B.; Ulas, T.; Skjelland, M.; De Nardo, D.; Labzin, L. I.; Kerksiek, A. et al. Cyclodextrin promotes atherosclerosis regression via macrophage reprogramming. Sci. Transl. Med. 2016, 8, 333ra50.

[26] Di Cagno, M. P. The potential of cyclodextrins as novel active pharmaceutical ingredients: A short overview. Molecules 2017, 22, 1.

[27] Sana, B.; Johnson, E.; Lim, S. The unique self-assembly/disassembly property of Archaeoglobus fulgidus ferritin and its implications on molecular release from the protein cage. Biochim. Biophys. Acta 2015, 1850, 2544-2551.

[28] Besenicar, M. P.; Bavdek, A.; Kladnik, A.; Maček, P.; Anderluh, G. Kinetics of cholesterol extraction from lipid membranes by methyl- $\beta$ cyclodextrin-A surface plasmon resonance approach. Biochim. Biophys. Acta 2008, 1778, 175-184.

[29] Tobias, R.; Kumaraswamy, S. Biomolecular binding kinetics assays on the octet platform. FortéBIO 2014, 14, 1-21.

[30] Buecheler, J. W.; Howard, C. B.; de Bakker, C. J.; Goodall, S.; Jones, M. L.; Win, T.; Peng, T.; Tan, C. H.; Chopra, A.; Mahler, S. M.; et al. Development of a protein nanoparticle platform for targeting egfr expressing cancer cells. J. Chem. Technol. Biotechnol. 2015, 90, 1230-1236.

[31] Li, L.; Fang, C. J.; Ryan, J. C.; Niemi, E. C.; Lebrón, J. A.; Björkman, P. J.; Arase, H.; Torti, F. M.; Torti, S. V.; Nakamura, M. C.; et al. Binding and uptake of H-ferritin are mediated by human transferrin receptor-1. Proc. Natl. Acad. Sci. USA 2010, 107, 3505-3510.

[32] Kwon, C.; Kang, Y. J.; Jeon, S.; Jung, S.; Hong, S. Y.; Kang, S. Development of protein-cage-based delivery nanoplatforms by polyvalently displaying $\beta$-cyclodextrins on the surface of ferritins through copper(I)-catalyzed azide/alkyne cycloaddition. Macromol. Biosci. 2012, 12, 1452-1458.

[33] Rosenbaum, A. I.; Zhang, G. T.; Warren, J. D.; Maxfield, F. R. Endocytosis of beta-cyclodextrins is responsible for cholesterol reduction in niemann-pick type C mutant cells. Proc. Natl. Acad. Sci. USA 2010, 107, 5477-5482.

[34] Li, W.; Xu, L. H.; Forssell, C.; Sullivan, J. L.; Yuan, X. M. Overexpression of transferrin receptor and ferritin related to clinical symptoms and destabilization of human carotid plaques. Exp. Biol. Med. (Maywood) 2008, 233, 818-826.

[35] Fenyvesi, F.; Réti-Nagy, K.; Bacsó, Z.; Gutay-Tóth, Z.; Malanga, M.; Fenyvesi, É.; Szente, L.; Váradi, J.; Ujhelyi, Z.; Fehér, P. et al. Fluorescently labeled methyl-beta-cyclodextrin enters intestinal epithelial caco-2 cells by fluid-phase endocytosis. PLoS One 2014, 9, e84856.

[36] Loftsson, T.; Brewster, M. E. Pharmaceutical applications of cyclodextrins: Basic science and product development. J. Pharm. Pharmacol. 2010, 62, $1607-1621$.

[37] Bachman, J. Site-directed mutagenesis. Methods Enzymol. 2013, 529, 241-248. 